\title{
Mapping experience in reportage drawing
}

\section{Louis Netter}

\begin{abstract}
Reportage drawing is a revelatory act that combines the challenges of quick, gestural drawing with a level of accuracy in the depiction of people and places. Add to that the complications of working in sometimes hostile or at the very least, less than ideal environments and you have a highly unique drawing act. Reportage drawing, through its quick execution necessitated by environmental flux and other conditions, also provides a window into the genesis of the drawing. The momentary, intuitive process fluctuates between the observed, the imagined and the remembered. Looking at the way in which the drawing is rooted to the in-situ experience and notions of place, artists engage in reportage in highly individual ways, balancing intent with the demands of observation in fluid environments. Experience here is two-fold, the experience of negotiating the location and the experience of drawing itself. Through interviews conducted with reportage artists Jill Gibbon, Gary Embury and my own work and reflections, the aims and intentions of the artists will be compared and contrasted and tensions between the journalistic and social commentary aims will be explored through individual practice. Jill Gibbon's practice and research is looking at the potential in reportage drawing for political, even radical expression. Her War Mart work is explored here which clearly reveals her reportage process, secretly drawing at an arms trading event in London and creating evocative commentary through her hurried, immediate drawings. Gary Embury is the editor of the Reportager website which provides a crucial platform for contemporary reportage practice. His work is characterised by raw observation and his declared aims for his work are journalistic. This work has great immediacy and reveals the simultaneity between observation and action in drawing. Through a narrative of the experience creating their work in differing environments, the work will be seen as the summation of experience and the complex intentions and self imposed limitations of the artists, contributing to an intimate look at contemporary reportage practice.
\end{abstract}

\section{Mapping experience in reportage drawing}

Reportage drawing is a complex activity bringing together layers of experience, acquisition, intention and reflection. Through my own practice, and the practice of other reportage artists, I seek to identify in the reportage act the unique affordances of on-the-spot drawing for articulating complex and layered ideas about the places they depict. The drawings, both individually and as a whole, map out an experience that is both idiosyncratically the artist's and, gestures to a wide range of commentaries. These are both intentional and unintentional and point to the ways in which artists value the act for purging the contrivances of their own presuppositions and agendas.

Reportage, as I am defining it here, is the contemporary practice of drawing people and places in situ from observation, memory, imagination or some 
combination thereof. Practitioners approach the act in differing ways but the work is necessarily shaped by direct experience and artists, without exception, engage in an inevitable dialogue between themselves and the nature of their drawing practice. This work is often removed from the expectations and confines of commissioners and represents highly personal practice that extends the artist's thematic considerations and the aesthetic potential of their drawing. This work, by virtue of its production, also provides a unique commentary on the potentiality of drawing as a means of documentation and as a distinctive filter from which to view the modern world.

This paper aims to demonstrate that the totality of the reportage experience is rooted in the circumstances of production and that the drawing itself is both intentionally and unintentionally imbued with the perceptual realities of fluid environments and the latency of artistic intent. The work of two practicing reportage artists and their own commentary upon their drawing will be discussed along with my own work and thoughts. Specific drawings will be referenced to highlight the narrative of their production and the formal choices of the artist in-situ.

The history of reportage drawing is rooted in the necessity for information. Botanical, geological and anthropological subjects dominate early reportage and were practised by artists groomed in the European academic styles that dominated the $18^{\text {th }}$ and $19^{\text {th }}$ centuries. Alongside the 'professional' artists, lay artists from the middle and upper classes kept their own sketchbooks and drew their surroundings for pleasure or posterity, rarely intending an audience for the work. (Berg 2008) The dominance of the objective practice of reportage was largely concerned with fulfilling the assignment (documenting the new world and conflicts) or testing the powers of artistic perception and skill. Lay draftsmen and women likely had the same aim although were limited by experience and skill, relying instead on a limited schematic vocabulary. (Berg 2008)

The latter half of the $19^{\text {th }}$ century saw the explosion of illustrated newspapers that required the skills of reportage draughtsmen to document a variety of subjects from the local to the global. (Hogarth 1986: 30) The designation of 'special artist' was given to those who travelled far and wide to cover conflicts and this exciting and sometimes dangerous job gave prominence to the artist's depiction of events. (Hogarth 1986: 30) Drawings still dominated the photograph in print, as photographic technology was both too cumbersome and limited in its ability to capture action. Although a great number of different artists contributed to these publications, the work collectively had a homogeneous quality due to the reproduction of the drawings as wood block prints. The transfer of the drawings often lent a sameness to them which is especially disappointing as the original drawings were often vivid and expressive, some sketched secretly on cigarette paper to avoid detection and the suspicion that they might be spies. (Hogarth 1986: 31). The artists used photographic reference when available but the work was primarily the result of observation and imagination in varying degrees, much like today. What is 
striking is that the resonant images one would have of the important events of the day would be drawings.

It wasn't until the $20^{\text {th }}$ century that reportage practice was valued not for its analogous connection to reality (like the photograph), rather, it is valued precisely because of its corporeal qualities, deriving its aesthetic properties from a self-reflexive engagement with experience through the affordances of drawing itself. (Berg 2008) Here, reportage is practiced and enjoyed precisely because it is unabashedly imperfect and represents singular (and therefore more symbolic and universal) vision.

The commonalities of practice within reportage drawing are clear but the ways in which artists work within these limitations and challenges is diverse in practice and intent. The act demands quick thinking and quick summative drawing. Often marked by a gestural approach, the work is executed quickly and demands a mixture of direct observation and memory to capture subjects in a fluid environment. The drawing is composed of reductive lines that synthesize the complexity of the environment and through rigorous practise, this economical application of marks becomes a short hand that resembles the complex symbolic forms of a language (although is more flexibly applied). The reportage drawing is marked with a kind of brevity that is evocative of place and, of the drawing process. The drawing, by virtue of its production, connects us to the lived experience of the artist. This is the crux of why reportage drawing holds a unique position among other forms such as photography. By revealing the hand, reportage drawing reveals the corporeal filter with which it is produced and mediated and, orients our understanding of the image as the product of an individual.

The spaces, places and people the artist chooses to depict in reportage drawing represent choices that are variously made before and during the act, typically crystalized only when committed to paper. From interviews and questionnaires with reportage artists, places and locations were of varying importance but the changing realities on the ground in those locations was paramount. What became apparent was that the circumstances around the making of the drawing contributed a great deal to the success or failure of the drawing. Equally remarkable was the extent to which minute details of the externalities around the production of a drawing were remembered after the fact. The drawings themselves encapsulated an experience and, in some drawings that will be referenced here, the environmental and circumstantial factors around the production greatly informed and shaped the work. In fact, in many cases, these externalities are very much a part of the work and align with the greater aims of the artist to elicit the rawness of direct and hurried observation. Indeed, my interviewees practise reportage drawing precisely because they are courting the unexpected and revelatory and see the act as vanquishing the preachments of their professional illustration 'styles'.

Reportage artists approach their subjects with differing agendas and interests. This is true of the way in which they experience places as well however, it is important to identify the ways in which we are defining place and the artist's 
experience of it. Places, as apposed to spaces, are those which we affix value to. (Tuan 1977: 6) Significant to the study of reportage drawing is how we see places as containers of ideas. Yi-Fu Tuan speaks of our unique capacity as human beings for symbolization and he forefronts experience of places over cultural expectation. (Tuan 1977: 5) Tuan also distinguishes place as a pause within a space. As Tuan notes 'each pause in movement makes it possible for location to be transformed into place'. (Tuan 1977: 6) Dewey offers another take on the pause situating it in experience noting 'there are pauses, places of rest, but they punctuate and define the quality of movement. They sum up what has been undergone and prevent its dissipation and idle evaporation.' (Dewey 2005: 38) It could be said that the act of drawing further prevents the 'dissipation' by recording experience. It could also be extrapolated from this that reportage drawing is necessarily a transformative act, imbuing drawn locations with the properties of place as they are manifest from drawn, symbolic forms.

While Tuan's interest in spaces and places is around perceptual experience, his elucidation of this process gives insight into the primacy of experience in reportage. Artists, like their partners in literature, have unique means for meditation on places and their meaning and can convey complexly layered experiences. Tuan notes:

To experience is to learn; it means acting on the given and creating out of the given. The given cannot be known in itself. What can be known is a reality that is a construct of experience, a creation of feeling and thought. (Tuan 1977: 9)

The confluence of feeling and thought is at the heart of reportage practice. While the act can overwhelm thematic considerations that emerge by virtue of the challenge of depiction, the navigation of a place is experiential, tangential and guided by core intellectual and emotional instincts. Tuan sees feeling and thought not on opposing ends of the spectrum as in subjective and objective states respectively, but as near the two ends of the 'experiential continuum' and both as 'ways of knowing'. (Tuan 1977: 10)

Dewey also sees experience as the merger of intellect and emotion but also of a kind of necessary interaction. He notes, 'direct experience comes from nature and man interacting with each other. In this interaction, human energy gathers, is released, dammed up, frustrated and victorious. There are rhythmic beats of want and fulfilment, pulses of doing and being withheld from doing.'(Dewey 2005: 15) This interaction achieves another level when the demands of the act further 'frustrate' the observer and the experience takes on a hyper level of acute awareness. Dewey also makes the important distinction of the active observer or participant in experience. This relates to the ways in which the reportage artist operates responsively and attentively in situ. In reference to the artistic experience broadly, he identifies the simultaneity of the act as such:

'As he watches what stirs about him, he, too, is stirred. His observation is both action in preparation and foresight of the future. He is as active through his whole being when he looks and listens as when he stalks his 
quarry or stealthily retreats from a foe. His senses are sentinels of immediate thought and outposts of action, and not, as they so often are with us, mere pathways along which material is gathered to be stored away for a delayed and remote possibility.' (Dewey 2005: 18)

Concurrent with purely observational and perceptual properties of place, artists and the drawings themselves are often concerned with the less quantifiable properties of place. Tuan, talking of how humans perceive architectural forms in planned cities noting, 'progress here is from inchoate feelings for space and fleeting discernments of it in nature to their public and material reification'. (Tuan 1977: 17) Similarly, reportage drawings evoke the echoes of past experiences, highly individual inclinations and sentiments that are neither planned nor intentional and can imprint the drawings with a unique sensory depth.

Extending this notion of inchoate, primal, sensory responses to place, Mazzoleni notes the qualities of experiencing the modern city as place as, 'the uncontainable quality of these elementary pulsations (both in their aspects of sorrow and exaltation) emerges violently in our contemporary consciousness in post-industrial cultures because the habitat here has clearly lost its ancient organic characteristics, its similarity to the body (as in the ancient cities)...'. (Mazzoleni 1993: 287) Mazzoleni sees this as establishing a 'modality of difference' and challenges the instruments of analysis, which, are typically concerned with removing this 'difference' instead of engaging the 'tragic intimacy of this difference'. (Mazzoleni 1993: 287) This friction between the hyper modernity of the modern city and the human actors operating within it is uniquely confronted in reportage drawing in both form and content. This occurs as the drawing is 'body' centred and, as Mazzonleni notes 'it is the body which makes metaphor possible, and which is at the centre of symbolic thought'. (Mazzoleni 1993: 288) The riddle of expressing the seemingly inexpressible flood of primal sensory experiences and free associative observations within the city is, at least in a highly subjective way, contained in the multitudinous act, and resulting record, of reportage drawing. The modern world is documented using an ancient language and we have a meta commentary about the friction between modernity and humanity embedded in the act of reportage.

Proximity to experience is key to reportage drawing but equally, and in an interconnected way, so is that of intimacy. Tuan also identifies intimate experiences as 'often those in which we become passive and allow ourselves to be vulnerable, exposed to the caress and sting of new experience. (Tuan 1977: 137)Both the intimacy of a unique perspective and, the intimacy of the artist's practice, revealing a privileged look at perceptual qualities of line and the machinations of the artist's thinking. Tuan notes that intimate experiences 'elude confident interpretation', but in reportage drawing, we have a concretisation of those experiences in the totality of a drawing.

Like all drawings, reportage drawings are read in two ways, often simultaneously. We have the subject matter and the way in which that subject is treated in the drawing. Philip Rawson called the subject or the pictorial content 
of the drawing the 'tenor', and, defines 'the topic', as the meaning within the subject due to its treatment through drawing. (Rawson 1969: 5) Rawson's 'topic' is highly variable and highly individual, requiring and accessing our knowledge of the visual language of the artist and our presuppositions about the artist's intentions. A successful drawing is a marriage of subject and treatment but it also much more. As the reportage drawing experience is a constellation of layers of experience, a successful drawing is, as Rawson notes a 'system of relationship' and that the drawings exhibit 'structural function represented by the qualities they show which enable them to be related to one another at the level of generality and system, so as to compose an intelligible whole'. (Rawson 1969: 35, 36) Dewey confirms this unity or totality noting, 'in a work of art, different acts, episodes, occurrences melt and fuse into unity, and yet do not disappear and lose their own character as they do so... The existence of this unity is constituted by a single quality that pervades the entire experience in spite of the variation of its constituent parts. (Dewey 2005: 38)

Jill Gibbon's work is marked with a visceral line that is charged with both political intent and the spontaneity with which she surreptitiously applies her marks. Gibbon's practice based PhD looked at reportage drawing as radical witness and makes a case for the potential in reportage drawing for political statement. Charged is an intentional word choice here as it relates to the root meaning of caricature and the nature of her work.(Petherbridge 2010: 346) Caricature need not be a damning moniker for the work but rather a means of identifying the formal qualities that exist and carry intent. In talking about the synthesized line at work in caricature, Gombrich notes:

'Here, too, a single feature often stands for the whole, and a person is represented by one salient characteristic only. To the caricaturist, however, this extreme simplification is not the starting-point of his work. He arrives there often by stages, beginning with a lifelike portrait which he somehow simplifies and distorts in the absence of the model.' (Gombrich 1938: 4)

In Gibbon's work, this reductive line is evident and, although bearing some relation to the 'parody, vulgarity and the grotesque' that marks traditions of caricature (especially the hybrid of reportage and caricature in the work of George Grosz), the work is equally shaped by the demands of the act and responsive, covert drawing. (Petherbridge 2010: 346) Also, the tendency toward caricature of some sort in reportage is often less intentional than might be thought and arises, organically, as a result of the demands of time and synthesis of the salient features of subjects (both human and otherwise).

Equally, beyond the confinements of the act and the in situ considerations, the artist's visual aesthetic, built up by a refinement of vision both inward and outward looking, constitutes an important layer to their visual language. George Grosz's distinct style, clearly informed by street level observation, was also heavily informed by his interest in puerile graffiti that he saw scrawled in men's lavatories. (Grosz 1993) Additionally, any grotesquery's that are evident are likely intentional and align with the evolving thematic interests in the drawings. 
Talking of Ruskin's views of the grotesque, Edwards and Graulund note 'grotesque forms distort proportion and problematize vision, making objects idiosyncratic and liberating the field of vision through the freedom of the imagination.' (Edwards \& Graulund 2013: 17) However symbolic the forms of the grotesque may be, Mary Russo 'relates grotesque bodies to the specificities of time, space and the dimensions of the modern spectacle' (Edwards \& Graulund 2013: 14) In this way, the grotesque indulgences of the reportage artist are not diversions from the present, but are reactions to wholly specific instances and observations and, by virtue of their more synthesized form, connect to the universal as well as the singular. The aim of the grotesque is often an elevation of experience through a kind of theatrical arranging of incongruous parts and sheds the concerns for accuracy towards a 'perfectly imperfect whole'. (Edwards \& Graulund 2013: 19)

For Gibbon, the consideration of place is key as she has secretly entered and drawn in rarely observed arms fairs that represent the darkest parts of capitalist enterprise. She notes 'Sometimes, I choose a location because it is hidden, and I think it should be open to public scrutiny, for instance an arms fair. Here, getting access is as much a part of the project as the drawings.'(personal communication) Place is then the setting of this drama that she intends to capture as a carnivalesque theatre of vile archetypes being wined, dined and seduced in absurd (although observed) scenarios. The arms fair represents a kind of hypermodern conception of place in which globalism has distorted the connection to the producers of goods and 'mobility' has a potentially corrosive effect on morality. (Cresswell 2004: 24). Gibbon's drawings address this with the banal and tawdry human interactions foregrounding the consequential sale of sophisticated arms. Equally crucial, as she notes, is the access to the location and the manner with which she needs to produce the drawings which in this case is covert. In reference to fig.1 below, she describes her process:

In Fig1, I noticed a flirtatious encounter in an arms fair that seemed to sum up the decadence of the arms trade. I started the drawing by focussing on the facial expressions. Then, I drew the rest of the pose, speeding up to get as much of the situation as possible. When drawing in arms fairs, I avoid looking at the page, because I don't want it to be obvious that I am drawing, so the result is chaotic. The people in Fig1 soon moved but I think it describes something of the encounter, and the arms trade. The unfinished quality of the drawing also conveys the illicit manner in which it was drawn. 


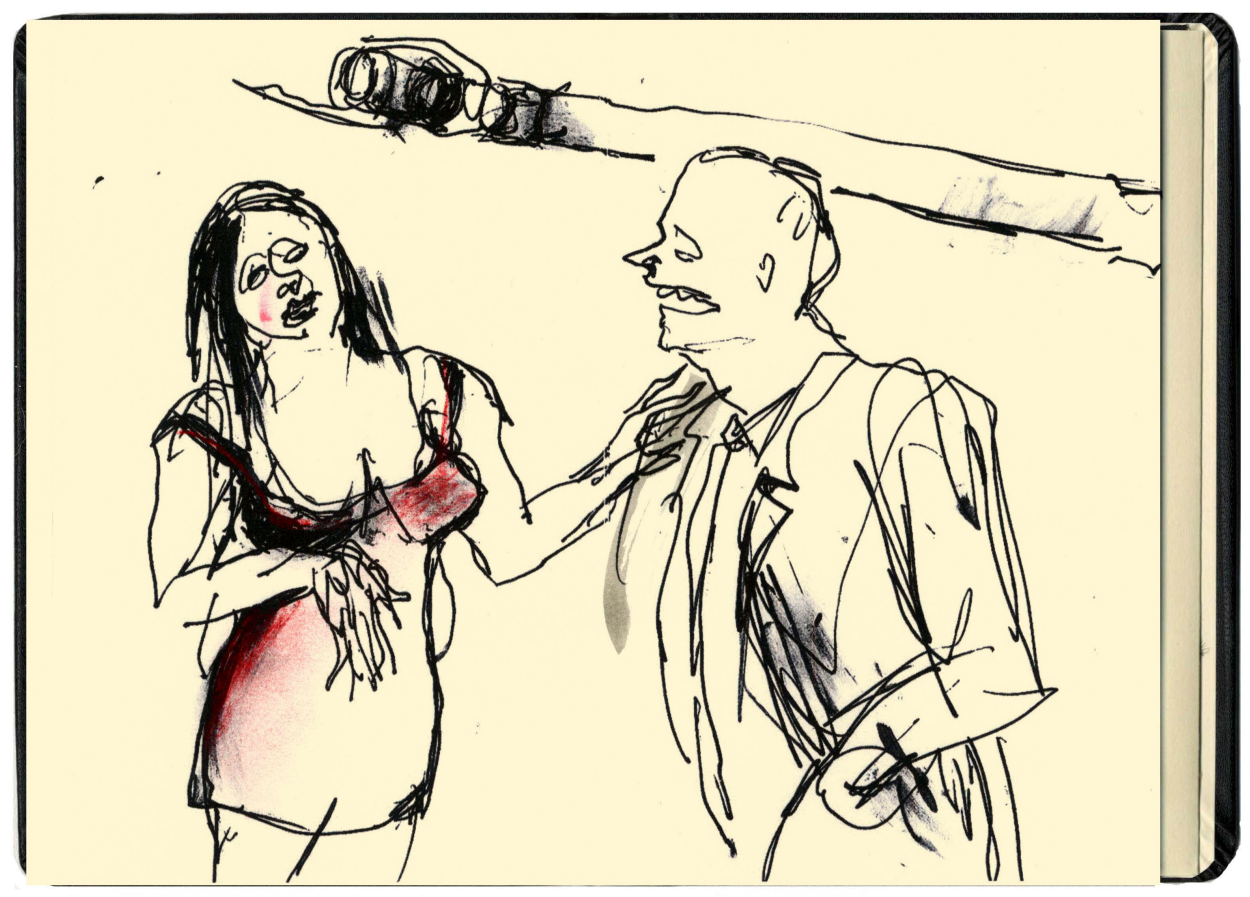

Fig. 1. Jill Gibbon

As with much reportage drawing, the manner of production is highly relevant to the resultant drawing and often represents for the artist one of the key motivating factors of the act; Namely, the production of highly expressive, unexpected and unself-conscious drawing. Artists also work within parameters and limitations to ensure this immediacy and connection to a distinct observed experience. Gibbon, in response to the function of memory in her drawing notes 'I sometimes complete a drawing after the figures have moved, from immediate memory. However, I avoid adding to drawings after I have left a venue, when I no longer have direct experience of the place.' (personal communication) These limitations set by the artist act to maintain the connection to the place and the resulting aesthetic achieved through rapid, hurried and hidden execution of the drawing.

The drawing, in this case, is an illicit act much like the lascivious protagonists in the drawings. The scrawl of marks and the gestural indications compel us, simultaneously, to the execution of the drawing and the commentary they exert. Both readily observable properties of the drawing, the manner of execution and subject matter, unify in our experience of the drawing and we connect to the psychic world of the artist and their direct experience of the event. While we may perceive an economy of line that starts to depict a 'type' rather than a specific person, this too is an evolution of reportage practice. Rawson describes 'type' as 'the product of an accumulation of graphic patterns' (Rawson 1969: 246) Rawson furthers 'for type in this sense is an optical construct, based upon patterns of form assembled into groups which, because they are used repeatedly, become to some extent conventional' (Rawson 1969: 246,247) Through an engaged reportage practice in which one would be developing a visual shorthand necessary for quick denotation, it is not unreasonable to expect these patterns to 
repeat and even formulate schematic 'types' that are flexibly applied and reapplied. The extent that they become conventionalised is another consideration that practitioners in reportage would contend is unintentional and worse, undesirable.

Reportage artists explore place in various ways and with differing agendas. For Gibbon, she admits premeditation in the choice of arms fairs for furthering her political views but admits 'the more subtle themes of commodification, prostitution, and desperation are informed by the experience of the place. I knew nothing of the drama of an arms fair until I entered one.' (personal communication) Jill exhibits openness to the experience of place and we are also privileged to see, in the drawing, the development of her thinking. Dewey says of the experience of thinking (and we might say of thinking and drawing) '...premises emerge only as a conclusion becomes manifest. The experience, like that of watching a storm reach its height and gradually subside, is one of continuous movement of subject-matters.' (Dewey 2005: 39) Indeed these moments as captured in Fig.2 below, can expound on or contradict preconceptions and make new revelations possible by virtue of unexpected scenarios and juxtapositions. These unexpected scenarios translated in drawing, either re-establish existing beliefs or create new associations (whether they be political or social, overt or subtle).

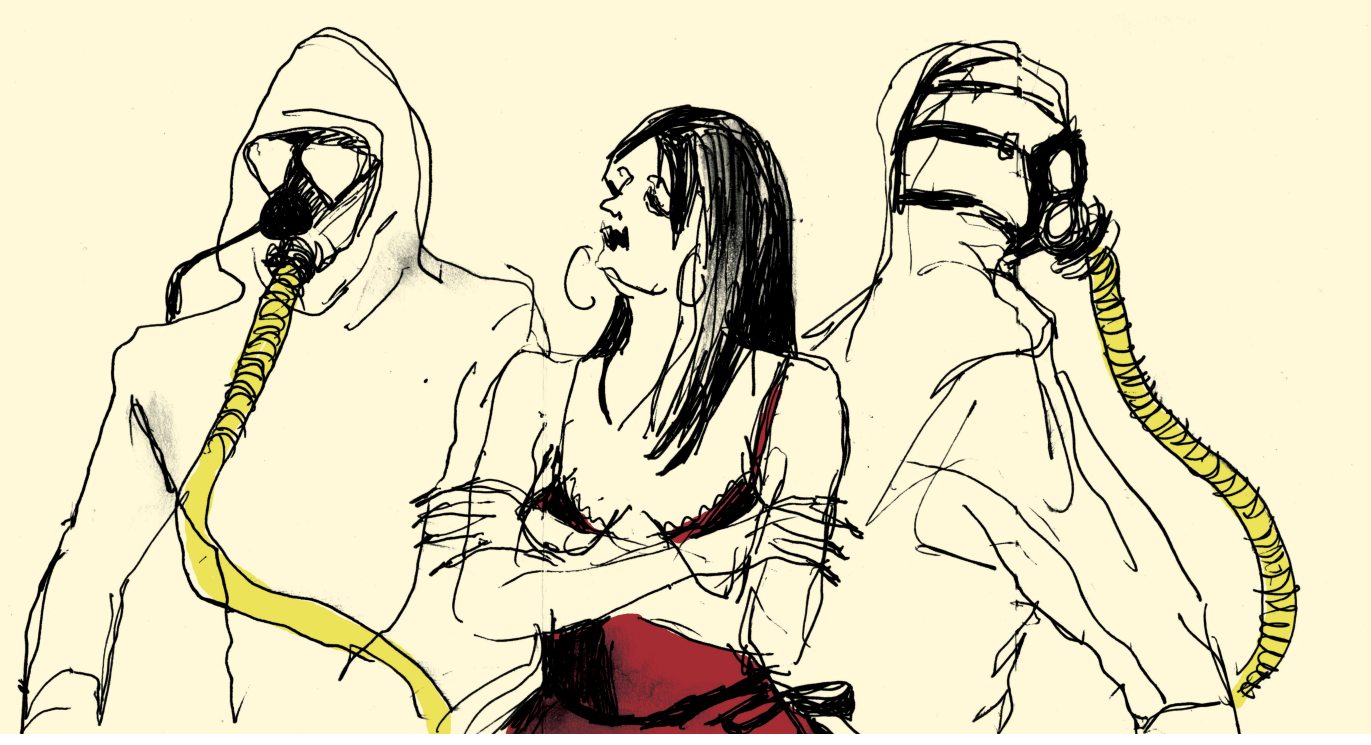

Fig.2, Jill Gibbon

The immediacy of depiction and framing is a well hidden conceit of some reportage drawing that is often constructed with some intention of pulling together observed subjects and making purposeful compositions. Gibbon notes this saying 'I often construct scenes, juxtaposing figures and backgrounds as I walk through a venue' (personal communication). Referencing Fig. 2 she says 'Fig2 I started with the sales woman, and added the mannequins from elsewhere in the hall. By showing her, arms interlocked with mannequins, I wanted to imply the commodification of the arms trade, where products take the place of people.' (personal communication). This construction, while a fabrication, is still 
produced on the site. Like the above discussion, reportage artists see the location as more than a site of observation but a container of ideas and the drawings themselves, move beyond depiction towards a flexible manipulation of observed subjects and their contexts. Jill importantly adds, 'I don't think reportage drawing necessitates the construction of scenes. Sometimes I simply draw a fragment - a passing expression, or half-seen figure, for instance Fig 3 (see below). What matters is that the drawing conveys something of the situation.' (personal communication). Furthering this statement, the duality of reportage is that it necessarily contains both observation and fabrication, and that its ultimate goal of capturing the essence of place is as much about a selecting eye as it is an observing one. In regards to a kind of truth that may be perceived in her reportage drawing Gibbon notes, 'A situation can only ever be interpreted from a political, historical, and emotional perspective. For this reason, I prefer to talk about representations. Reportage drawing offers a representation of a situation, from one person's point of view. I use drawing methods that emphasise my emotional and political responses to a situation to demonstrate that the image is partisan, not an objective truth.' (personal communication). As demonstrated later, this is not the contention or aim of other reportage practitioners and points to a significant division in the practice between those artists who court thematic material and those who are more responsive to circumstantial shifts on the ground.

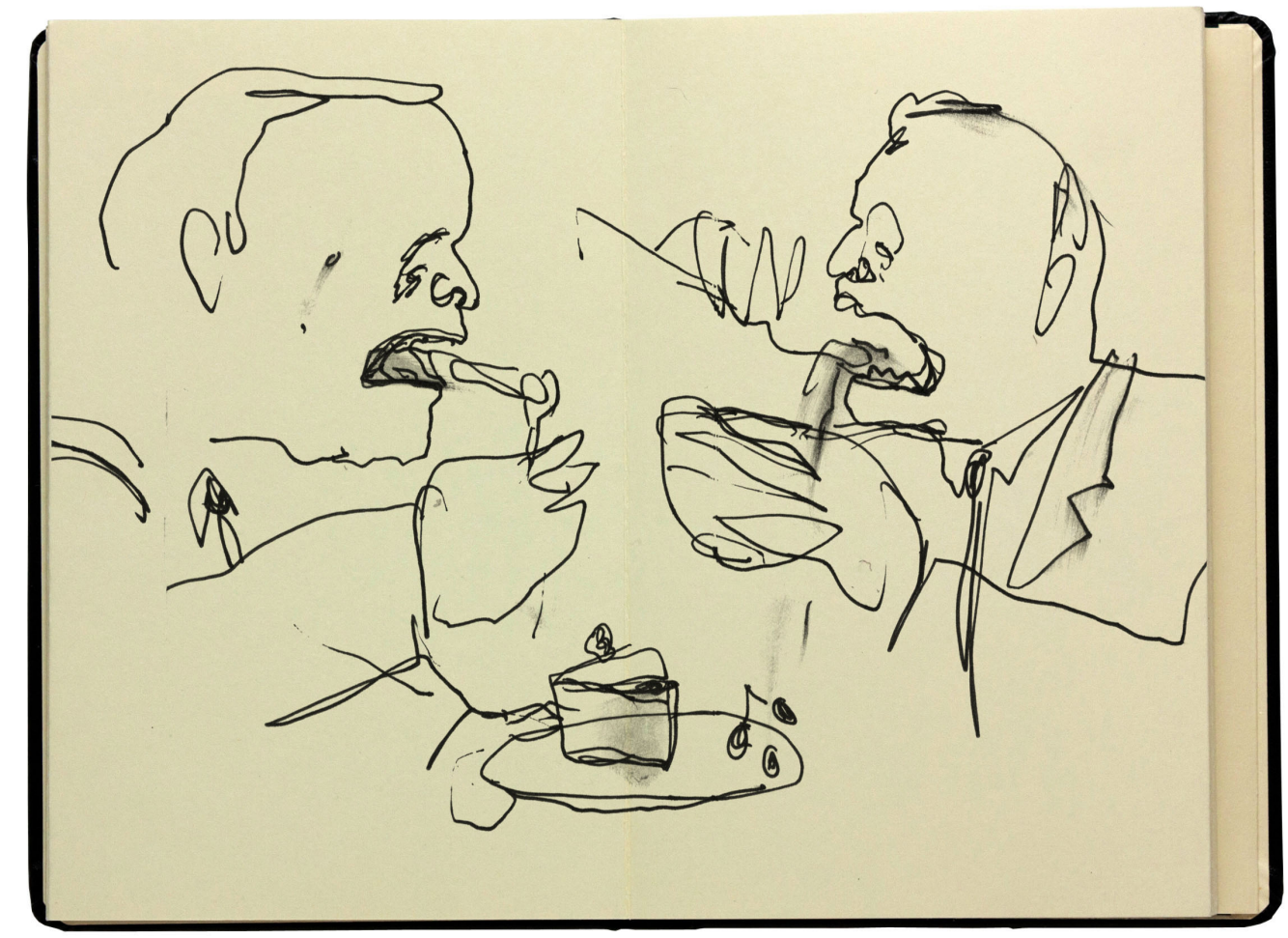

Fig.3, Jill Gibbon

Gary Embury's work is anchored in core fundamentals of reportage drawing such as direct observation and mark making and is imbued with the experiential 
properties of the in-situ drawing experience. As Rosand notes about the unique accessibility of drawing 'in drawings we most directly encounter the artist. The very openness of the medium denies the draftsman any place to hide and exposes him to us, unawares.' (Rosand 2002: 19) This is particularly evident in Embury's drawings that revel in the affordances of drawing for relaying the direct articulation of form. Rosand sees this mark making within drawing as creating a 'hermeneutic space' and that the drawing 'suggests the responsive dynamics mandated by that openness, the necessity of interpretation, as the viewer negotiates the referential options of the line (Rosand 2002: 20)

Embury approaches the places he draws with differing preparations. With planned locations he does considerable research and negotiation with people involved in the location. This was particularly true with Embury's on going Bike Project work in Bristol. The terms of his drawing residency had to be negotiated along with how he was going to proceed with the project. On location, Embury believes one should be ready for anything on site and he is always at the ready with pencil at hand. On this point, Embury tells of an anecdote about an occasion he drew his sick son:

I am going to refer to a drawing of my son in A and E (Fig. 4). It was New Years Day and he had a really severe asthma attack so I drew whilst we were waiting, it sounds a bit callous considering he was suffering a bit and did some drawing of people in the waiting room but also just started drawing while he was on the, I forgot what it's called when you are having a severe asthma attack. I think the nurse was a little taken aback that I was callously drawing him while he was struggling to breath but it was a great opportunity to get some drawing done in a location that I would not normally be in. 


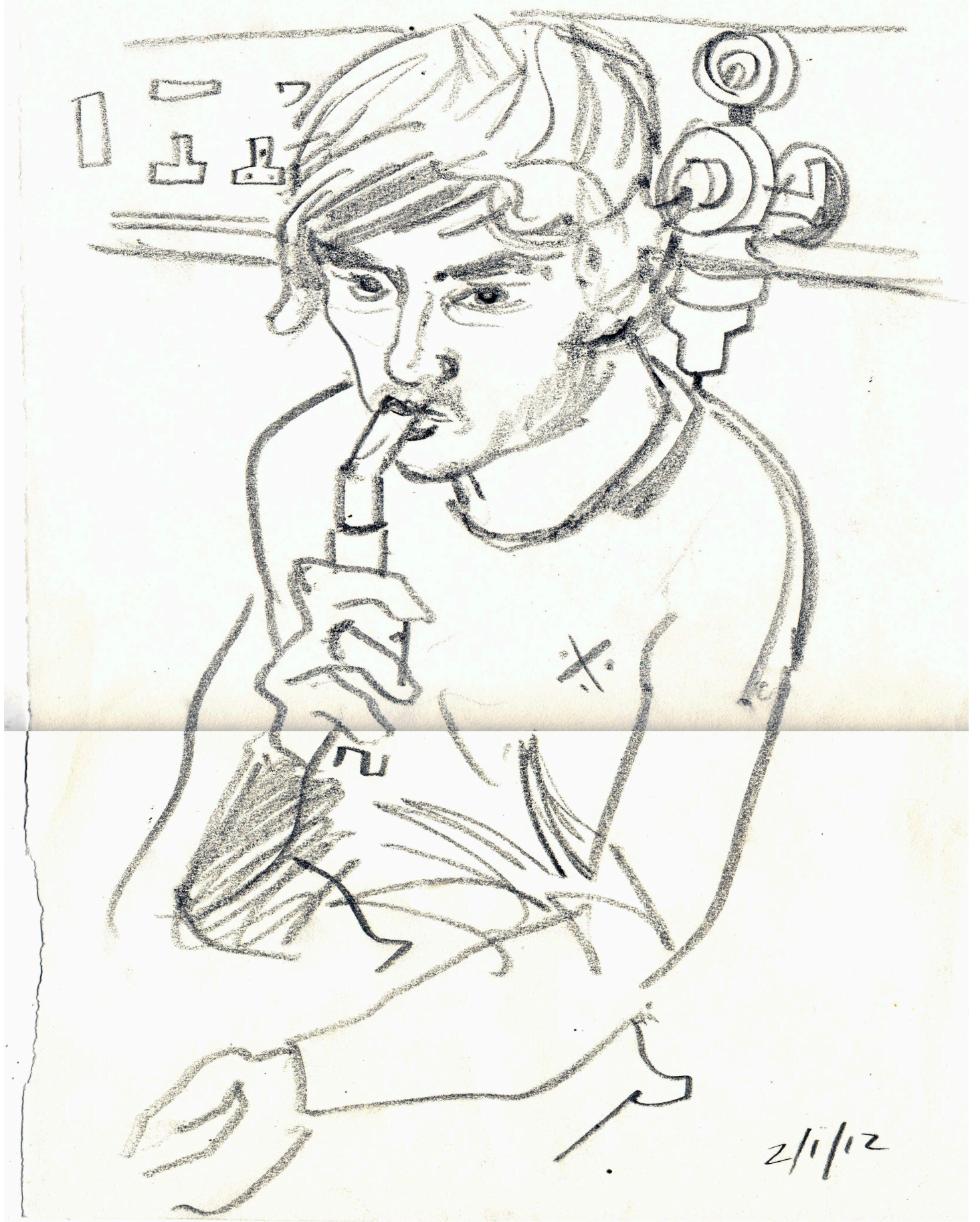

Fig. 4., Gary Embury, Josh in A\&E

With Embury's reportage, like that of Gibbon, the location and the circumstances of the production of the drawing play a central role in the drawings success or interest. Embury's thick, confident lines are marked with both heavily synthesized reductive lines and quirky, idiosyncrasies that arise out of hurried production.

His aim for doing planned and negotiated projects such as the Bike Project is, as he describes, journalistic. His methodology chimes with that as he notes: 
I am trying to draw regularly and look at projects that are not just about the aesthetics of the place but there is an underlying issue that maybe I can get some narrative out of by either talking to the people involved or interviewing them. Often it is not as formal as that. They start talking to me and you get a narrative out of the location so it is not just about drawing is also about finding out about what their story is. Which I think is quite interesting. So you have the drawing and then you have the other level of journalistic inquiry which is their story, their narrative. (personal communication)

Embury's journalistic aims for his work provide a set of daunting limitations that he is fully aware of. There is an intentional confinement to direct observational drawing and this is central to the vitality he seeks in his work. In reference to a drawing trip last year with the Topolski residents (reportage drawing program) to Notting Hill Carnival, Embury notes how a challenging environment becomes the story. Equally it demonstrates the ability to recall highly specific circumstances surrounding drawing in a location:

The residents (artists) struggled initially because it was so full and some of the things we were drawing seemed a little voyeuristic, it was a little bit uncomfortable but the girls didn't seem to give a damn they were just getting ready for the carnival. The actual location was quite dark so the figures were silhouetted against the windows. It was an incredibly dynamic, moving location and situation, which I found, well...I could have stayed in there all day. Some of the residents who struggled a bit more with figure drawing didn't quite know how to tackle it. For my part it always takes maybe 10-12 minutes to loosen up. A little bit like an athlete trying to loosen up before a race. Your first drawings are quite contrived and then you start thinking you have to record what's in front of you and then you start making connections and you are not being as analytical and you are thinking, yeah maybe I'll leave that out, you start editing on the fly. (personal communication)

As noted earlier, the desire by the reportage artist to purge the drawing of contrivances is crucial and you can see in Embury's comments an enthusisasm for the challenge of the task and a sense that success in drawing is about locking into the rhythm and pace of a location. Here, unlike Gibbon's work, we do not see a declared political of social intent within the work (see fig.5) rather we see the results of direct observation and the notational qualities of drawing. Embury even uses the term 'time based' to describe his drawings and notes, 'I feel it is more of a time based medium if you are in a location that is constantly moving and in flux. And that is what I like...more the abstract nature and mark making becomes very fluid.' (personal communication) Rawson notes that drawings, although read in their static form, have an 'implied pattern of those movements through which it was created' and that appreciating drawings 'one has to be continuously aware of the character and qualities of the sequences which went into their composition.' (Rawson 1969: 15) Because of the nature of mark making with Embury's work, we are connected to the synergy between the mark 
and the implied forms and sense, as he notes, the 'time based' properties of the drawing.

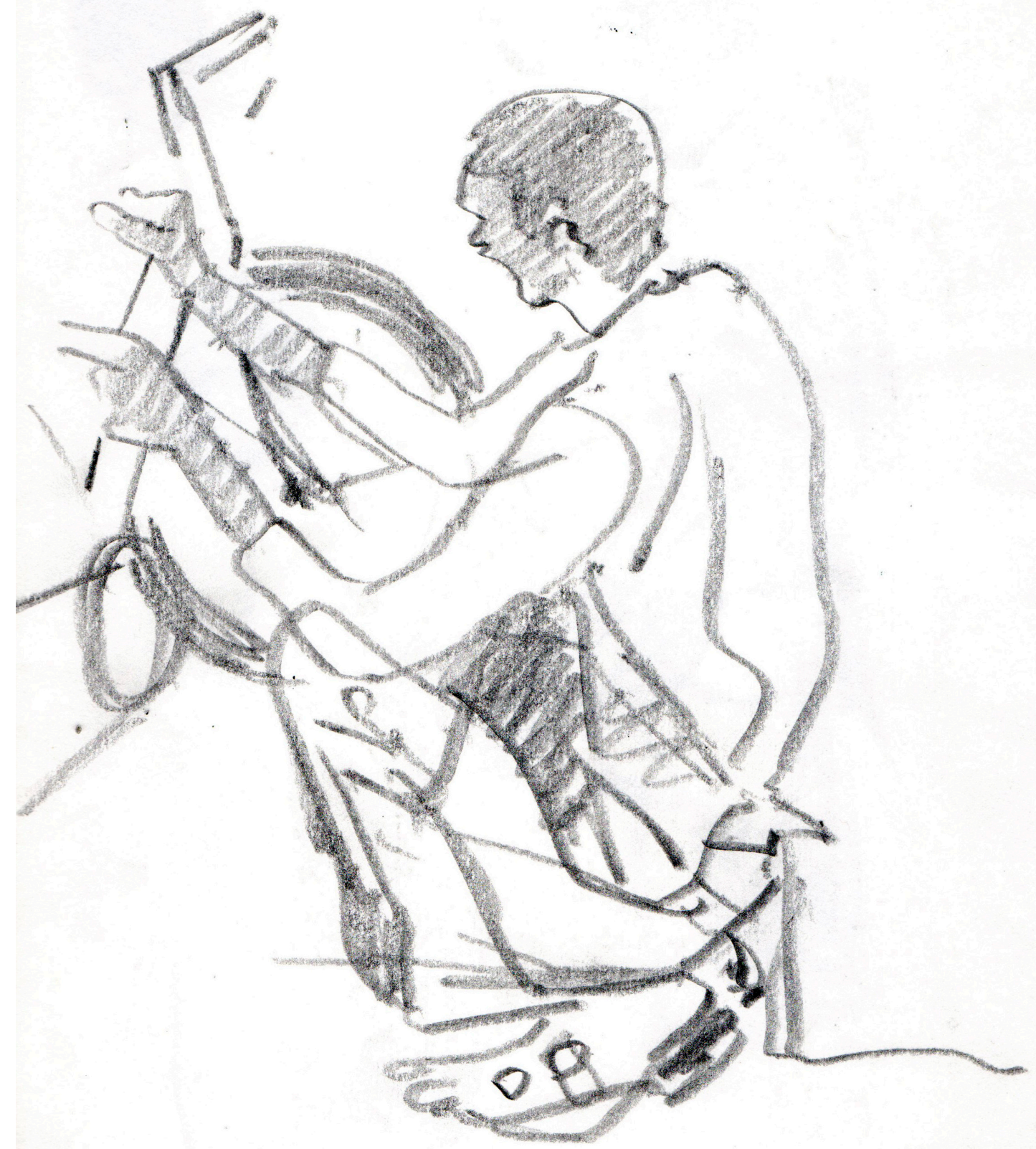

Fig. 5., Gary Embury, Bike Project

The limitations that Embury imposes upon his reportage methodology result in some compelling atmospheric drawings that synthesize layers of experience within a fluid environment. The drawing above reflects this kind of experience for Embury as he notes:

I had been trying to draw him all day and I got bits of back and head and neck, ear and then after two or three hours I literally drew that in one but I suddenly realised that he kept on going back to that pose. He is incredibly long limbed. He's from Somalia and has amazing proportions, his hands and I thought, yes that has been informed by the last three 
hours of failed drawings. I obviously knew in my head that pose. I wasn't aware of it but when I did it so quickly it felt so fluid.

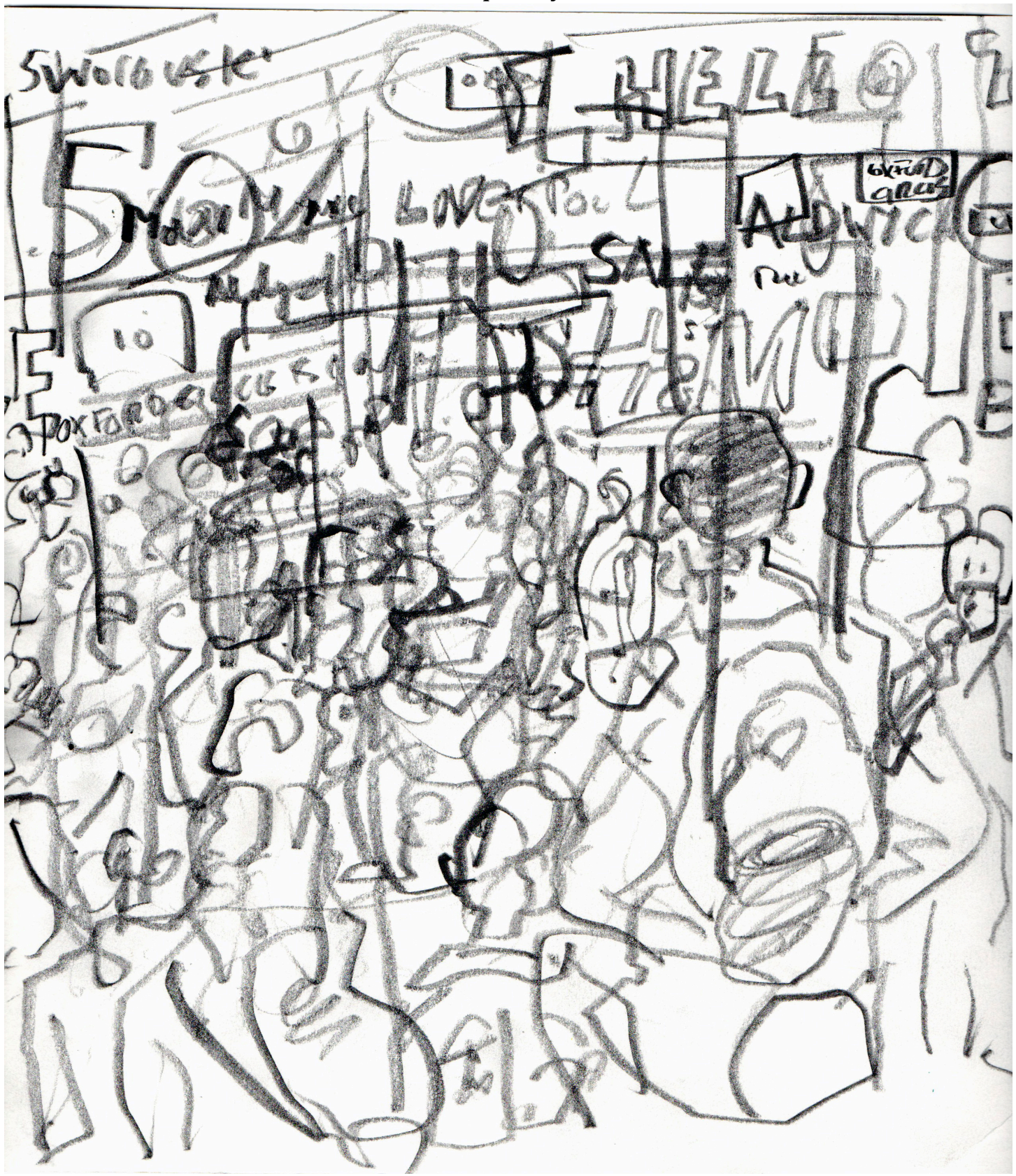

Fig. 6, Gary Embury, Oxford Circus

Another drawing that seems to crystalize this layering of experience is Fig. 6 which depicts Oxford Circus during the Christmas holidays again with the Topolski residents. Making it clear that it was not an intentional spot to stop and draw, Embury also made the point that even in planned drawing locations he is interested in the unexpected. His remarks about the drawing and the experience of drawing it were in response to a question about themes. As noted above, Embury particularly, is interested in the serendipitous and themes and concepts that emerge do so through a successful communion with experience, not premeditated intent. He describes the circumstances of the above drawing as such: 
It was just before Christmas it was absolutely manic and I sat quite high up on a metal railing and ended up with this drawing which was really chaotic and much more overlaid than what I would normally do but...it was absolutely overwhelming. The amount of buses coming in front of me with huge typography and a guy with a loudspeaker urging people to shop, it was like something out of Bladerunner. I was completely overwhelmed by information. So I started drawing the typography, people overlaying...it became a very time based exercise. I don't know whether I did it intentionally but I emphasised hell, although it was hello kitty a big advert or something, I can't remember if I emphasised it because it was hell, people swirling around Oxford Circus going into the tube. There was shouting, we had some mad man come up to us being really obscene and grabbing the cameras.(used for filming the students drawing) The drawing, I am really pleased with it. It's chaotic.

This description and the rawness of the drawing speak to an intentionally limited filter between the practicalities of drawing and experience. As Dewey notes 'experience in the degree with which it is experience is heightened vitality. Instead of signifying being shut up within one's own private feelings and sensations, it signifies active and alert commerce with the world; at its height it signifies complete interpenetration of self and the worlds of objects and events.' (Dewey 2005: 18) This 'interpenetration' feels apparent in his description and the drawing as we see the walls between experience and depiction disappears. We also have a unique connection with the experience of the artist in this drawing. As Rosand notes, 'our experience of the drawing involves the reenactment of the drawing gesture, our mimic re-creation of the creative acts'. (Rosand 2002: 23) Our perception of this drawing as chaotic, lively and in a kind of perpetual motion echoes with Embury's description of it's making. And this is precisely the point for Embury. He notes that 'honesty and integrity' are the things he likes most about reportage and it is evident in his work that close proximity to the perceptual, procedural aspects of drawing in situ provides him the greatest rewards. The nearness to ocular perception bristles in the drawings and do lend a kind of authenticity to the work. This authenticity claim can be made on Embury's stated intentions for his work and how the work is read which, as noted, reflects the immediacy and confluence of observation and documentation. While Gibbon distances herself from the notion of reportage drawing being analogous with reality, it could be said her methods and aims bare a similar authenticity, although for the authentic depiction of felt experience rather than correspondence with what is seen. Comparing drawing to photography Embury notes 'the work has a different energy than photography'. (personal communication). While photography operates in a different sphere than reportage drawing, Embury's work does function as journalism and the debate about how, or even if, drawing could be wholly objective seems to interest him within his work.

My own reportage practice sits between the charged caricature of Gibbon and the raw observation of Embury. The work is concerned with the street level dramas that exist in urban environments and the stark contrasts between societies winners and losers. Focused primarily on people, the work is rooted in 
the tradition of caricature (particularly British and French) that saw the drama of every day life as a springboard for social commentary and a flexible stage for the construction of images. Like Gibbon, George Grosz is a major influence and his stylized, schematic depiction of his fellow Berliners enabled me to see the potential in a reportage that, while anchored in observation, was imbued with searing commentary. Although less overtly stylised, wholly constructed and reductive, my intention for the work is for the drawing to possess both the impression of a directly observed subject and carry a kind of inherent, implicit commentary. It is important for that commentary to be imbedded within the drawing itself and for that comment to be suggestive rather than explicit. Because the choice of subject is made in the fluid, in-situ environment, the subject, and therefore the subject matter is not fixed until the drawing is complete. This unexpected quality of reportage drawing is vital to its sustaining interest to me. As Embury notes above, this openness to the circumstances on the ground and the potential drawing opportunities it provides is integral to the total experience of reportage drawing and the courting of serendipitous discovery over pre-meditation.

The drawings are symbolic of either the location (as with fig. 7 below) or some universal human condition as in Fig.8. All of the drawings emerge out of walking around a location and typically looking for some time before I pick up a pencil. Like Gibbon and Embury (discussed above), the work has to be produced on location for it to contain the experience in the mark making. External and atmospheric conditions in-situ plays a role in the formation of the drawing as these conditions affect the drawing and choices of subject. Because my drawings are often concerned with people on the fringes of society, the weather is often an unseen subject itself. In Fig. 8, the homeless man was underdressed for mid winter and his depiction with sullen features and rail thin body, exerts the impression of desperation and our own blindness to the subject's plight (as implied by the quickly moving crowd behind him). The ways in which these subtle themes can be uncovered in the act points to the way in which the act resolves many sub conscious layers of observation and comment in drawing. Many if not all these layers of meaning are only evident upon the completion of the drawing and many more impressionistic ideas become evident upon further, close reading of the resultant drawings. 


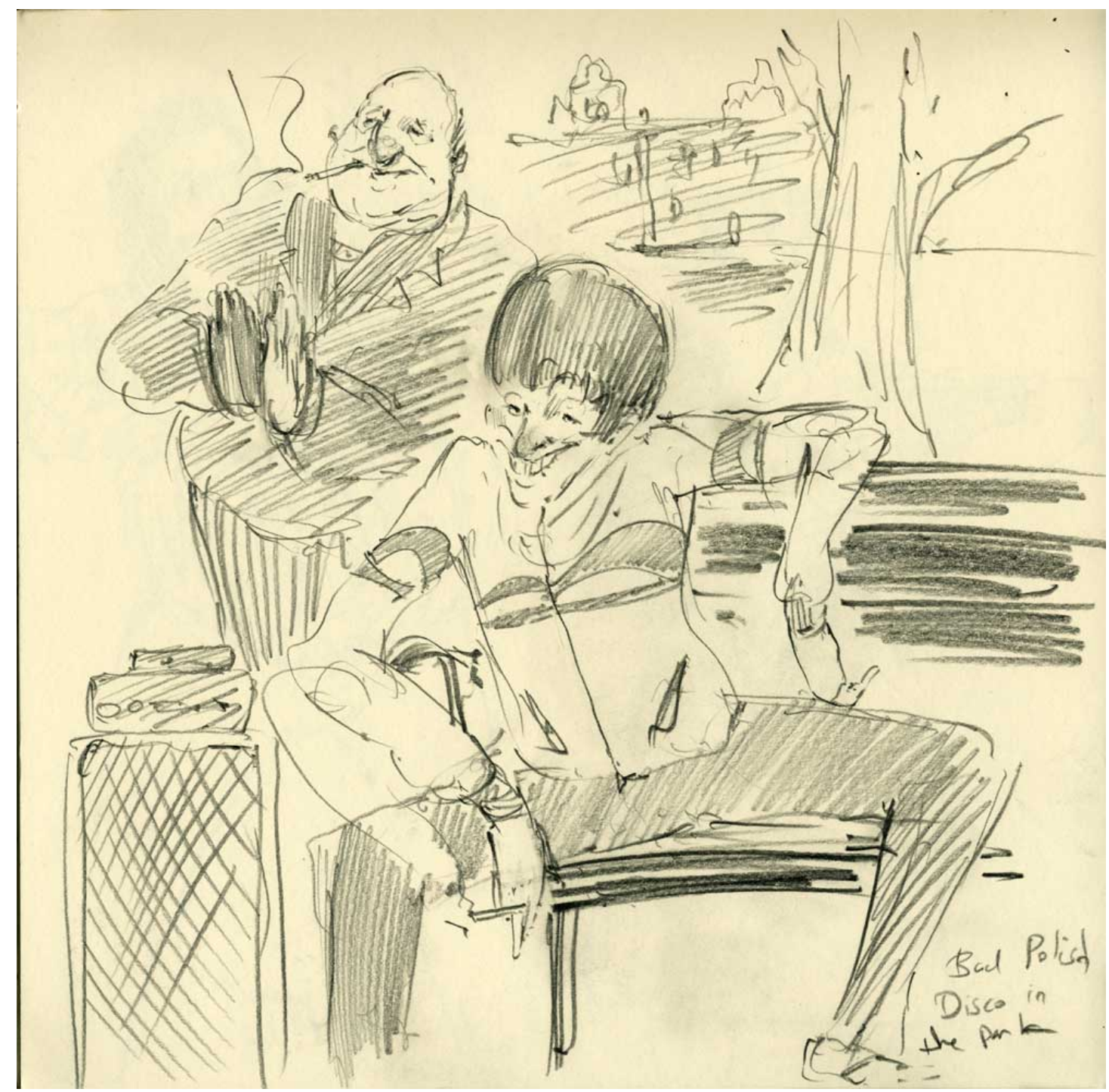

Fig. 7, the authors drawing, Poland

The circumstances around the production of the drawing above (fig.7) confirm the premise of experience as central to the act of reportage. It was a Saturday night in a park in the small industrial city of Bydgoszcz in Poland. The park was filled with amorous couples, families and young people gathered to listen to some music. The music was provided by a skinny young man in a tracksuit who had a large speaker and a microphone. The music was a kind of eastern European disco that incorporated some polka beats. The moment that I chose to capture was the self satisfied and enraptured young man and a clapping spectator behind him.

The drawing is an observation and a construction. Although not seen in exactly this pose, this was the spirit of the observed moment. To construct a drawing is a decision one must make when drawing in-situ as the environment is often too fast moving and circumstances too difficult and exposing to draw directly (being detected drawing by your subject can problematize the situation, causing, occasionally, offense). The construction was the merger of my working memory of the scene and my direct observation of what I could piece together in the location. Although constructed, the drawing does reflect my own directly 
observed experience and, although clearly laden with commentary and even caricature, like Gibbon, this drawing is as much a record of thought and opinion as it is of observation. Although far from the direct observation of Embury, the work is the product of lived experience and a range of observed and felt impressions, specific to this time and place. Going back to Rawson's concept of the 'tenor' and 'topic', here the two unify in the expressive gesture of the main figure, highlighting the way in which reportage drawing compresses the artist's multiple concerns in reductive lines. The 'tenor' here is impossible to extricate from the topic and like most reportage drawings, the pictorial content is volatile up until the point of completion (as in this drawing which only after completion makes a humorous comment upon Polish fashion and the earnest un-coolness of this young man). The inherent lack of pictorial control and the on the fly nature of the work cultivates surprising imagery and often less conventionalised approaches to drawing.

Psychogeographer Ian Sinclair notes in his book 'Lights out for the Territory' that the practice of urban wandering has shifted from the flaneur towards 'the age of the stalker' and walking is with 'a thesis' and 'a prey'. (Coverley 2010: 120) This resonates with my own reportage practice. There is the intent to commence drawing at the start of a journey but the subjects are identified and drawn as they become of interest. Once a subject is identified they are indeed stalked and studied. The study and recording (an intense kind of visual remembering) of the characters is especially important considering the fact that on occasion, they are drawn after the fact. This level of observation is deep and occasionally helped with notations about dress, physical characteristics, identifying qualities of the location and other specifics. I often remember the scene well enough to recall it in a drawing. It is an act of commune with my prior experience sufficient to represent, and indeed re-experience it in a drawing.

The drawing is comprised of quickly rendered gestural marks that are constituents of a visual shorthand, compressing meaning into notational mark making. The commentary is evident because the drawing does more than bear witness to an event, it comments upon it and extends it. The temporality of the moment becomes fixed in a drawing and we can see here that the operative and communicative parts of the drawing are the faces and the body language.

Because the drawing functions both in isolation and as a body of work, it could be seen as a closed, independent thought and therefore a piece of illustrative work. It does more than suggest its content, it affirmatively creates a space for the viewer to experience (or re-experience) the time and place. This space of communal experience we have with the artist in a drawing like this constitutes a micro culture of sorts. We have language, the expression of that language and we have context. The singularity of reportage drawing is in how these constituent parts vary among practitioners and how they negotiate the demands of the act with their own strengths and limitations. 


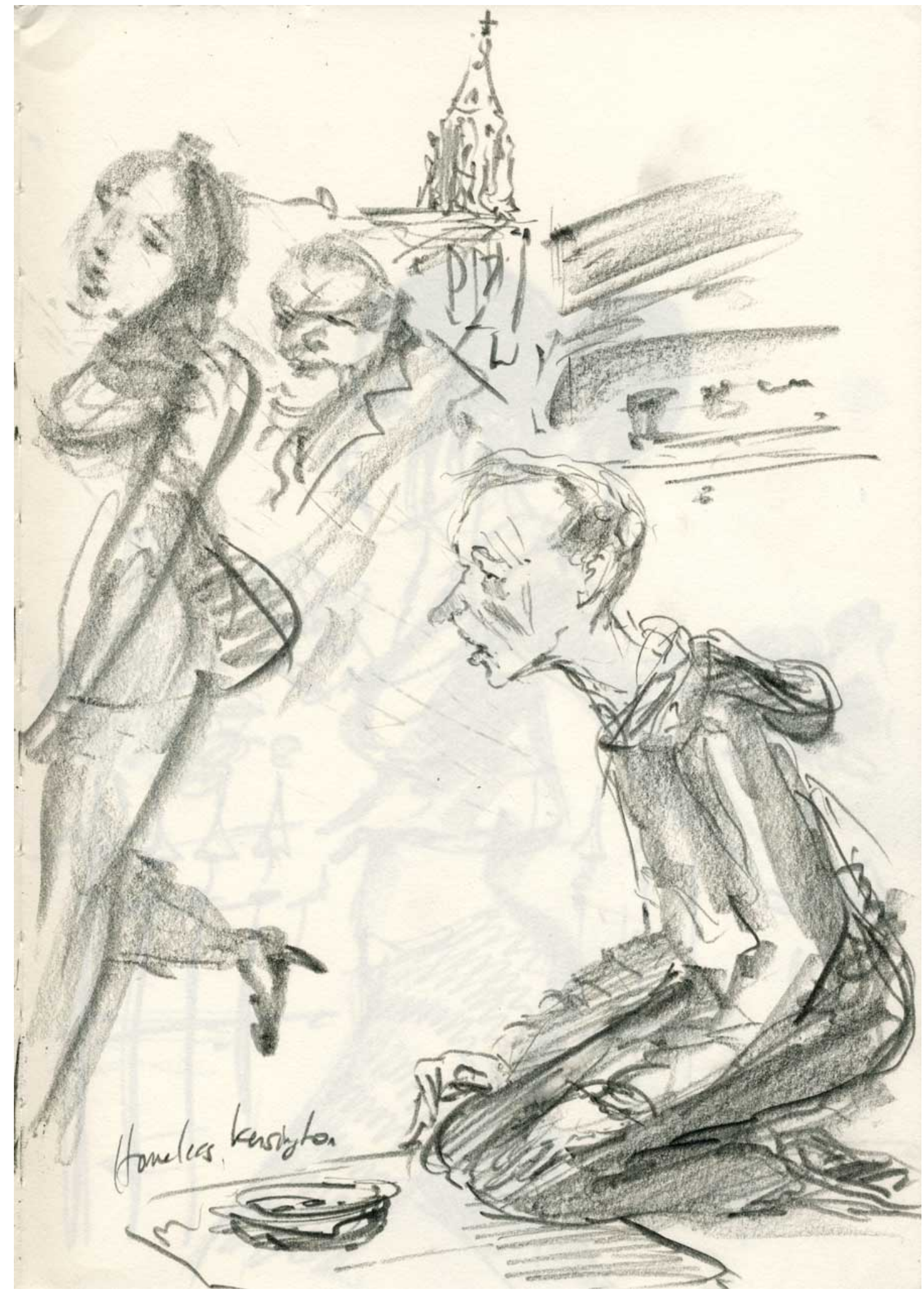

Fig. 8, The authors drawing, Homeless in Kensington

For the drawing above (Fig.8), the gesture of the figure was the primary subject, as the leanness of the man with his mouth agape seemed to speak to both fragility and a sculptural stillness, out of step with the surrounding rush but equally, ever present, timeless. These kinds of observations evolve through the 
act of drawing as a kind of second experience unfolds. The layers of the experience then emerge and revelations surface that evaded me in the first instance. This is true whether the drawing is done on site or after the fact. The drawing then represents a kind of settling of ideas and the drawing's success, for me, becomes a crystallization of the real and the symbolic. The drawings that don't work are the ones in which the departure is too great from the original subject and the personhood I aim to capture. Whether it is a ruse or not, the currency of reportage drawing is in it's connection to observed reality. If one perceives the work to be a total piece of fiction it lapses into a different form and loses vitality.

Reportage drawing is the summation of an individual experience in the singular visual language of the artist. The sustaining interest in the act for artists is the two-fold confrontation with ones own artistic powers and limitations and commerce with locations and their inhabitants. Further research and practice will look into the notion of space and place and how the contemporary practice of reportage celebrates mediated experience while implicitly and explicitly offering commentaries upon our modern world. 
Bibliography

Berg, S, Groos, U 2008, (Diving Trips) Drawing as Reportage, exhibition catalogue, 2008, Melton Prior Institut, Düsseldorf.

Connelly, F. (2014). The grotesque in Western art and culture: The image at play. Cambridge, UK: Cambridge University Press.

Coverley, M. (2010). Psychogeography. Harpenden, Herts: Pocket Essentials.

Cresswell, T. (2004). Place: A short introduction. Malden, MA: Blackwell Pub.

Dewey, J. (2005). Art as experience. London, UK: Perigee.

Edwards, J., \& Graulund, R. (2013). Grotesque (1st ed.). London, UK: Routledge.

Gombrich, E. (1938). The Principles of Caricature. British Journal of Medical Psychology, 17(Trapp no.1938a.1), Pp.319-42.

Grosz, G., \& Nisbet, P. (1993). The sketchbooks of George Grosz. Cambridge, Mass.: Busch-Reisinger Museum, Harvard University Museums.

Hogarth, P. (1986). The artist as reporter. London, UK: The Gordon Fraser Gallery Limited.

Mazzoleni, D. (1993). The City and the Imaginary. In Space and Place: Theories of identity and location (1st ed., pp. 285-301). Trowbridge: Redwood Books.

Petherbridge, D. (2010). The primacy of drawing: Histories and theories of practice. New Haven: Yale University Press.

Rawson, P. (1969). Drawing (1st ed.). London: Oxford U.P.

Rosand, D. (2002). Drawing acts: Studies in graphic expression and representation (1st ed.). Cambridge, UK: Cambridge University Press.

Tuan, Y. (1977). Space and place: The perspective of experience. Minneapolis: University of Minnesota Press. 